\title{
A hybrid model for mapping simplified seismic response via a GIS-metamodel approach
}

\author{
G. Grelle, L. Bonito, P. Revellino, L. Guerriero, and F. M. Guadagno \\ Department of Sciences and Technologies - University of Sannio, Via de Mulini 59/A, 82100 Benevento, Italy \\ Correspondence to: G. Grelle (gegrelle@ unisannio.it)
}

Received: 9 January 2014 - Published in Nat. Hazards Earth Syst. Sci. Discuss.: 3 February 2014

Revised: 23 May 2014 - Accepted: 9 June 2014 - Published: 14 July 2014

\begin{abstract}
In earthquake-prone areas, site seismic response due to lithostratigraphic sequence plays a key role in seismic hazard assessment. A hybrid model, consisting of GIS and metamodel (model of model) procedures, was introduced aimed at estimating the 1-D spatial seismic site response in accordance with spatial variability of sediment parameters. Inputs and outputs are provided and processed by means of an appropriate GIS model, named GIS Cubic Model (GCM). This consists of a block-layered parametric structure aimed at resolving a predicted metamodel by means of pixel to pixel vertical computing. The metamodel, opportunely calibrated, is able to emulate the classic shape of the spectral acceleration response in relation to the main physical parameters that characterize the spectrum itself. Therefore, via the GCM structure and the metamodel, the hybrid model provides maps of normalized acceleration response spectra. The hybrid model was applied and tested on the built-up area of the San Giorgio del Sannio village, located in a highrisk seismic zone of southern Italy. Efficiency tests showed a good correspondence between the spectral values resulting from the proposed approach and the 1-D physical computational models. Supported by lithology and geophysical data and corresponding accurate interpretation regarding modelling, the hybrid model can be an efficient tool in assessing urban planning seismic hazard/risk.
\end{abstract}

\section{Introduction}

In earthquake-prone areas, microzonation studies assume a main role in urban planning and managing seismic risk. For this purpose, several studies have been proposed by authors with the aim of consolidating knowledge on local amplification (e.g. Grasso and Maugeri, 2012; Bianchi Fasani et al., 2008; Scott et al., 2006; Thuladar et al., 2004; Maresca et al., 2003) or introducing methods and procedures aimed at evaluating or estimating seismic site response (e.g. Papadimitriou et al., 2008; Kienzle et al., 2006; Jimenez et al., 2000). Microzonation studies are developed at three different detail levels and depths (ISSMGE-TC4, 1999), depending on the type and amount of geological, geotechnical and geophysical data available. In contrast to the first two levels, the third level of detail analytically quantifies the seismic response by providing building design parameters. Many building codes, like Eurocode 8 and FEMA 356 (2000), require seismic design actions to be expressed in terms of spectral acceleration at surface level, derived from spectral acceleration at the bedrock level in combination with the amplification due to the sediment column.

In addition to a need to have a sufficient amount of information suitable for the seismic microzonation approach, computerized data management and spatial distribution in terms of input and output/outcome is also a requirement. Therefore, Geographic Information Systems (GIS) contribute the most to maximizing the available data in assessing or estimating ground-motion amplification (Kolat et al., 2006; Ganapathy, 2011; Hashemi and Alesheikh, 2012; Turk et al., 2012; Hassanzadeh et al., 2013) as well as seismicinduced effects (Grelle et al., 2011; Grelle and Guadagno, 2013). In this regard, the literature suggests approaches based on either experimental geophysical methods, such as dynamic low-strain (linear) measurements, mainly from ambient noise, or numerical simulation methods of linear or non-linear stress-strain response during shear-wave propagation in the layered cover. In such experimental methods, GIS are largely used in the spatial distribution of predominant 
site periods and related amplification factors (Al Yuncha and Luzon, 2000). The methods based on microtremor records do not investigate the possible non-linearity effects of the dynamic stress-strain behaviour and seem to provide good results in geological settings characterized by high-impedance contrasts (Bonnefoy-Claudet et al., 2009). However, these methods are largely used due to the fact that they are more expeditious and low cost (Mukhopadhyay and Bormann, 2004).

In microzonation studies carried out using numerical methods for estimating and evaluating the seismic site response, GIS provide the spatial distribution of parameters that characterize the seismic motion. Kienzle et al. (2006) approached the microzonation of Bucharest by creating a multilayer geological model and interpolating the values obtained from the transfer function analysis, in map node points, by using linear modelling software such as Proshake (EduPro Civil System, 1999). In the microzonation of Barcelona (Jimenez et al., 2000), the seismic risk hazard was assessed by using the SERGISAI methodology. In this case, the site response analysis was performed using the 1-D linear equivalent method of SHAKE91 (Idriss and Sun, 1992), which assumes a system of homogeneous, horizontally layered viscoelastic soil deposits. Automated procedures for calculating seismic soil response have been introduced recently. In these procedures the calculation of multivariate regression functions is modelled on the response outputs of 1-D non-linear analysis collected in the regional Hellenic data set, HelGeoRDaS, for different layer soil sequences and input motions (Papadimitriou et al., 2008).

Building upon the above-mentioned numerical methods, this study presents a hybrid model that is capable of predicting a spatial simplified seismic response by coupling GIS and metamodel procedures.

The hybrid model is based on a GIS model with a layered structure mainly performing a vertical pixel to pixel calculation using and producing data for and from associated "external-GIS" processes. Among the external GIS processes, the metamodelling (modelling of model) assumes the main role. Metamodelling consists in numerical data-driven models training on data output of physically based models aimed at emulating (approximately) the performance of the physically based models themselves (Doebling et al., 2002). In this way the metamodel permits a fast expansion of the analysis to a greater number of cases. Therefore, the success of these methods on the simplified description of natural phenomena depend both on the regression accuracy and robustness of the regression model chosen, its calibration (Sen and Akyol, 2010) and on the choice of suitable physical models in the training.

The proposed approach provides spatial distributions of the spectral acceleration response or spectral amplitude response following the seismic-lithological setting, which is generally modelled on all the quantitative and qualitative (regional knowledge) data sets on the seismic subsurface. This approach makes it possible to minimize the well-known errors and limitations linked to the use of the spatial interpolation method when it is applied to highly irregular spatial data such as seismic response parameters. In addition, the hybrid model is based on a GIS metamodel calibrated on a geophysical and geotechnical local database. This last aspect gives the model the opportunity to be re-calibrated when the data set is upgraded.

The hybrid model was applied to the built-up area of San Giorgio del Sannio village in southern Italy, where a large amount of geological, geotechnical and geophysical data were available.

\section{Hybrid model}

The hybrid model architecture is characterized by clusters of procedures and sub-models (Fig. 1) where data flow and information are driven in a semi-automated way using a tool code written in Python 2.7 (van Rossum and Drake, 2001) allowing a fast calculation mainly for regression iterations (Monte Carlo technique) and calibration processes.

The code is currently being improved with regard to greater automation and user-friendliness. The main clusters and sub-models of the hybrid model are: (i) The GIS $\mathrm{Cu}-$ bic Model (GCM) introduced in this study, (ii) a metamodelling process and (iii) pre-processing procedures of inputs on numerical and cartographical data sets. Stemming from this data set, the data/information flow occurs in sequence cascades between the various clusters, with the exception of a final loop between the GCM and the metamodelling process.

\subsection{GIS cubic model (GCM)}

GCM is a simplified and parameterized geometric model of underground half-space. In this way, GCM is a pseudo-3-D physically layered model based on feature sets and rastergrid calculations. In the first step, it executes a sequential calculation of raw and pre-treated input data. Subsequently, in the second step, it performs the calculation of data from metamodelling processes driven by instructions from the first step.

The GCM is based on two main elements: layer and zone (Fig. 2). The layer corresponds to a "litho-dynamic unit" with specific lithology and dynamic properties. This "lithodynamic unit" is mainly defined in terms of a shear-wave velocity depth-depending curve, and by its non-linear dynamic behaviour. The depth depending curves result from the regression analysis of $V_{\mathrm{S}}$-depth values, which are obtained both from depth and surface seismic geophysical surveys as well as deriving from penetration test parameters or other $V_{\mathrm{S}^{-}}$ correlated parameters from field tests. The layer is a geometric entity that extends over the entire area but it identifies the corresponding litho-dynamic unit (assuming physic entity) only where this latter is present. The zone is identified 


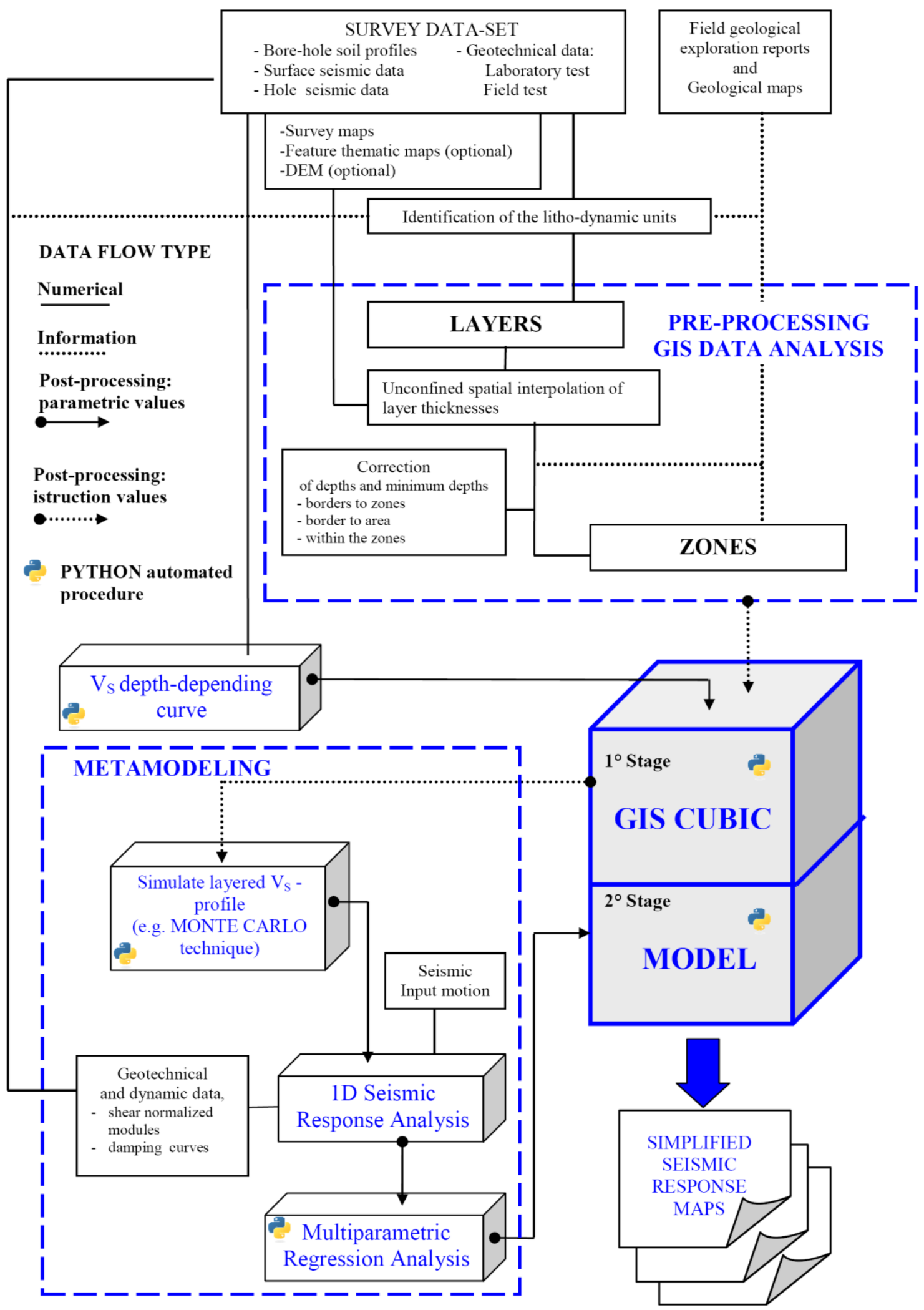

Figure 1. Flow diagram of hybrid model architecture. 


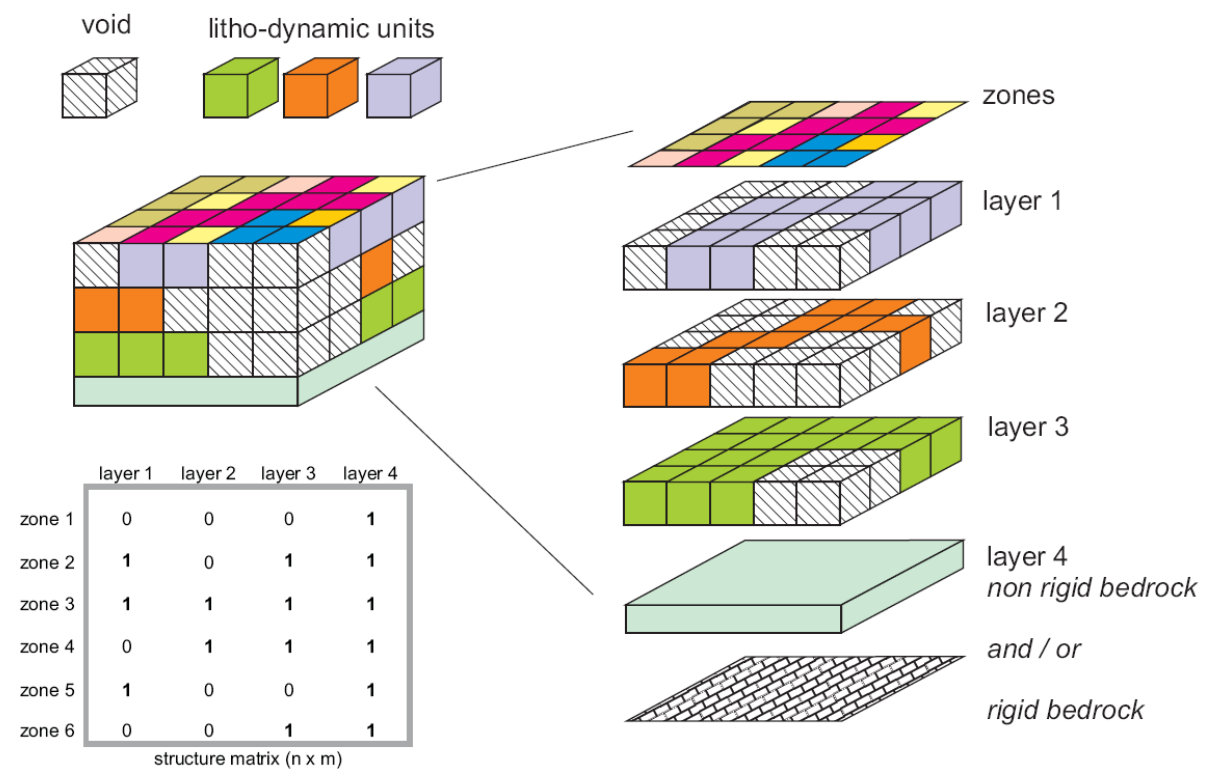

Figure 2. Subsoil half-space modelling by the GIS cubic model and structure matrix; an example using four layers.

by the vertical combination of litho-dynamic units in relation to their presence/absence in the layer sequence.

The model is set on a "matrix structure" having dimension $n \times m$, where $n$ is the number of $i$ layers constituting the fields of the polygon features, and $m$ is the number of $j$ zones forming the records of the polygon features.

The GCM claims that the number of layers is generally equal to the number of litho-dynamic units, but it may be greater when one or more litho-dynamic units are repeated in the sequence. The layer position in the sequence is usually in accordance with the chronostratigraphic relationship. In the matrix structure of $n$-layer sequence, a layer is defined as empty, assuming a value of 0 , when the corresponding lithodynamic unit is not present. Diversely, it assumes a value of 1 if the layer is filled (Fig. 2). Therefore, given an $n$-layer sequence, the maximum possible number of $m$ zones is $2^{n-1}$. The bedrock is the $n$th layer at the base of the sequence, and it is always present in a matrix structure assuming a value of 1 . A complete sequence shows all litho-dynamic units present in a study area. Two or more types of bedrock involve the multiplication of maximum possible zones in relation to the number of bedrocks.

\subsection{Preliminary analysis and identification of layers and zones}

The recognition and delimitation of the zones is a key point due to the fact that they entail the distribution of a 1-D layered model, and therefore the associated seismic response.

The geometrical delimitation of zones requires qualitative and quantitative data. A preliminary delimitation based on surface geology can be obtained from field surveys and pre-existing maps. The presence and therefore the spatial extension of litho-dynamic units in the layers is defined by understanding the combined data obtained from borehole drilling and surface geophysical surveys. The spatial distribution of the thickness of the layers is carried out by means of the map interpolation technique for the definition of the zones. Such a distribution is obtained by the identification of the litho-dynamic units and the interpretation of the lithostratigraphic profiles in accordance with available seismic logs. In a preliminary phase, the space identification of the litho-dynamic unit in the layer is associated with an assigned minimum layer thickness. Therefore, taking into account this aspect, layers that in seismic logs show a thickness less than the minimum layer thickness are considered empty and the thickness must be associated with the next litho-dynamic unit. Consequently, the zones have litho-dynamic sequences with a thickness not less than the minimum layer thickness. In the preliminary step, the unconfined interpolation of thickness can be performed for all the layers. In a second subsequent step, the values of layer thickness less than the minimum layer thickness are re-assigned to zero, indicating the absence of the litho-dynamic unit. In addition, the minimum layer thickness value corresponds to the depth at which the seismic response output is defined. This depth is usually associated with the mean foundation plane of a building.

\subsection{Shear-wave velocity depth-dependent curves}

The model requires that the shear-wave velocities associated with the cover layer are non-linearly depth-dependent according to a space-invariant function. The function is a nonlinear log for coverage layers:

$V s_{i}(z)=V s_{0_{i}}+\alpha_{i} \log (1+z)$. 


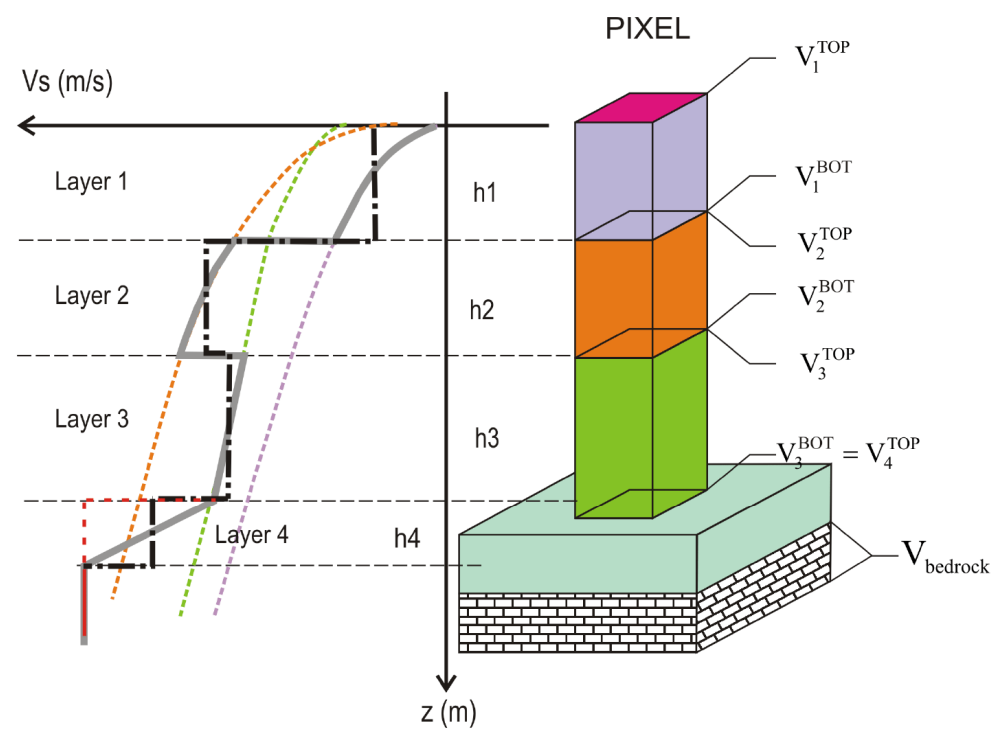

\begin{tabular}{|c|c|c|c|c|c|c|c|c|c|c|c|c|}
\hline & layer 1 & layer 2 & layer 3 & layer 4 & $\mathrm{~V}_{0} 1$ & $\mathrm{~V}_{0} 2$ & $\mathrm{~V}_{0} 3$ & $V_{0} 4$ & $\alpha 1$ & $\alpha 2$ & $\alpha 3$ & $\alpha 4$ \\
\hline zone 1 & 0 & 0 & 0 & 1 & 0 & 0 & 0 & <value> & 0 & 0 & 0 & <value> \\
\hline zone 2 & 1 & 0 & 1 & 1 & <value & 0 & <value> & <value> & <value> & 0 & <value> & <value> \\
\hline zone 3 & 1 & 1 & 1 & 1 & <value $>$ & <value> & <value > & <value> & <value> & <value > & <value> & <value> \\
\hline zone 4 & 0 & 1 & 1 & 1 & 0 & $<$ value $>$ & $<$ value $>$ & <value $>$ & 0 & <value > & $<$ value > & <value> \\
\hline zone 5 & 1 & 0 & 0 & 1 & <value> & 0 & 0 & <value> & <value $>$ & 0 & 0 & <value $>$ \\
\hline zone 6 & 0 & 0 & 1 & 1 & 0 & 0 & <value> & <value> & 0 & 0 & <value > & <value> \\
\hline
\end{tabular}

Figure 3. 1-D layered $V_{\mathrm{S}}$ profile and parameter matrix GCM - an example using four layers, three covered layers and one non-rigid bedrock.

Rigid bedrock assumes a constant velocity value. If the bedrock is not rigid, the model expects that the rigid condition is reached by a linear depth-dependent function:

$V s_{n}(z)=V s_{0_{n}}+\alpha_{n} z$ (when non-rigid);

with the condition that $\alpha_{n}=0$ (when rigid);

where $z$ is the depth, and $V s_{0}$ and $\alpha$ are the intercept and the gradient, respectively, obtained via the regression analysis of $V_{\mathrm{S}}$-depth data.

In predictive terms, the empirical shear-wave velocity curves given by Eqs. (1) and (2) are the best representative values as they take into account the increase of the stiffness due to the lithostatic load (Fig. 3). In agreement with the matrix structure of the GCM, the shape of the bedrock and cover layer functions takes into consideration the same number of coefficients. The linear-log function assumed for the cover layer seems to have a fit performance close to the threeparameter power function usually used in regression for $V_{\mathrm{S}}$ depth-dependent analysis (Robertson et al., 1995).

In non-rigid bedrock, the linear function establishes that the shear-wave velocity increases downward with the depth until this velocity assumes the value assigned to the rigid bedrock (e.g. $800 \mathrm{~m} \mathrm{~s}^{-1}$ ) (Fig. 3). In addition, there is the need for the intercept velocity of the non-rigid bedrock function to be greater than/or equal to the function of the cover litho-dynamic units. This aspect reflects a condition, and assumption, that non-rigid bedrocks must be more rigid than the litho-dynamic cover units and, therefore, they reach a rigid condition much quicker at a depth than these latter.

\subsection{First stage procedure in GCM}

A new matrix named "parameter matrix" with dimensions of $2 n \times m$ was added to the structure matrix. In both matrices, zero values are corresponding. Values introduced in the parameter matrix are real coefficients stemming from depth- $V_{\mathrm{S}}$ regression analysis. The structure matrix fields and the parameter matrix fields were converted to raster and distributed over the whole area. The raster parameters are layer ${ }_{i}, V s_{0_{i}}$, $\alpha_{i}$ and $h_{i(x, y)}$, and their processes (progressions) are the following raster mathematical operations:

i. The spatial limitation of the thickness of the layers, and consequently of the zones, is obtained through a raster-calculation cutting: $h_{i(x, y)}=h_{i(x, y)}^{*} \cdot$ layer $_{i}$, 
where $h_{i(x, y)}^{*}$ is the $i$ th-layer thickness raster obtained by usual spatial interpolation methods under an unconfined condition. The raster cutting sets to zero the possible interpolated residual thickness in zones where the litho-dynamic unit is not present.

ii. The shear-wave velocity at the top and bottom of each $n-1$ cover layer is obtained using the parameterized log-linear functions.

The vertical shear-wave velocity distribution of the cover layers can also allow inverted rigidity conditions in relation to their position (Fig. 3):

$$
\begin{aligned}
& V s_{i(x, y)}^{\mathrm{TOP}}=V s_{0_{i}}+\alpha_{i}\left\{\ln \left[1+\left(\sum_{i=1}^{n-1} h_{i-1(x, y)}\right)\right]\right\} \\
& V s_{i(x, y)}^{\mathrm{BOT}}=V s_{0_{i}}+\alpha_{i}\left\{\ln \left[1+\left(\sum_{i=1}^{n-1} h_{i(x, y)}\right)\right]\right\} .
\end{aligned}
$$

iii. With regard to rigid bedrock ( $n$th layer), it is defined by a unique value of shear-wave velocity.

When the bedrock is non-rigid (geological bedrock), it is possible to assign a thickness of $h_{n(x, y)}$ down to the rigid condition; in relation to this, the model necessitates the assignment of a shear-wave velocity to the rigid bedrock, e.g. bedrock velocity $V s_{n(x, y)}^{\mathrm{BOT}}=800 \mathrm{~m} \mathrm{~s}^{-1}$ (EC8 prEN1998). This parameter is therefore defined by the following equation:

$$
\begin{aligned}
h_{n(x, y)} & =\left(800-V s_{n(x, y)}^{\mathrm{TOP}}\right) / \alpha_{n} ; \text { where } V s_{n(x, y)}^{\mathrm{TOP}} \\
& =\max \left(V s_{n-i(x, y)}^{\mathrm{BOT}}, V s_{0_{n}}\right)
\end{aligned}
$$

where $\alpha_{n}$ is the gradient and the $V s_{n(x, y)}^{\mathrm{TOP}}$ is equal to $\max$ values between $V s_{n-i(x, y)}^{\mathrm{BOT}}$, the shear-wave velocity of the end cover litho-dynamic unit and the $V s_{0_{n}}$, the intercept value of the bedrock $V_{\mathrm{S}}$-depth regression curve. De facto, Eq. (6) takes into account the possible head rigidity increase due to lithostatic layer cover loads in non-rigid bedrock (relatively low $V_{\mathrm{S}}$ values) or this increase is not contemplated in the presence of quasi rigid bedrock (relatively high $V_{\mathrm{S}}$ values).

iv. The spatial distribution of shear-wave velocity at the top and bottom of the layers permits the definition of the raster of the average shear-wave velocity of each lithodynamic unit:

$$
\bar{V} s_{i(x, y)}=\frac{1}{2}\left(V s_{i(x, y)}^{\mathrm{TOP}}+V s_{i(x, y)}^{\mathrm{BOT}}\right) .
$$

v. The average shear-wave velocity defines the raster of the fundamental vibration period:

$$
T_{0(x, y)}=\frac{4 \sum_{i=1}^{n} h_{i(x, y)}}{\sum_{i=1}^{n}\left(\bar{V} s_{i(x, y)} h_{i(x, y)}\right) / \sum_{i=1}^{n} h_{i(x, y)}} .
$$

\subsection{Metamodelling processes}

The metamodelling process aims at obtaining prediction models generated and trained on an output data set resulting from a seismic site response analysis performed on the simulation of layered $V_{\mathrm{S}}$ profiles. In this way, the obtained model is used to predict the seismic response of similar layered $V_{\mathrm{S}}$ profiles in a simplified manner.

\subsubsection{Generation of vertical layering $V_{S}$ profiles}

The generation of the layered $V_{\mathrm{S}}$ profiles is performed by means of the Monte Carlo simulation technique of $n-1$ cover layers. This simulation technique is based on a uniform random distribution. It is suitable in a linear gradient and a multimodal distribution of the thickness of the layers. Alternatively, other simulation techniques based on the Gaussian distribution can be used for this purpose.

The choice of the thickness of the layers occurs within the assigned interval in which the maximum and minimum values are defined by the GCM. The thickness of the $n$th layer is zero in the case of rigid bedrock. Instead, when the bedrock is non-rigid, its thickness is the function of the depth reached by the cover layer sequence (Eq. 6) once the shear-wave velocities of the cover bed sequence are defined (Eq. 5). For a better prediction performance of the model, the number of profiles generated must take into account the width of the thickness of the existing interval and the number of layers that characterize each zone.

\subsubsection{1-D seismic response}

On the simulated layered $V_{\mathrm{S}}$ profiles that are representative of each zone, the seismic response is defined by numerical methods that compute the seismic wave propagation in the subsoil (e.g. EERA, SHAKE, and NERA). These methods are based on the 1-D shear-wave propagation from the rigid bedrock within a plane-parallel layered subsoil. In terms of total stress, the dynamic behaviour is analysed using a viscoelastic constitutive shear stress-strain relation. However other numerical models can be used. The calculation requires the basic seismic input and the layered $V_{\mathrm{S}}$ profiles which are parameterized in terms of shear-wave velocity $V_{\mathrm{S}}$ density, $\rho$, the reduction curve of shear normalized modulus $G / G_{0}$, and damping curves $D / D_{0}$.

In order to increase analysis accuracy, the layered $V_{\mathrm{S}}$ profile can be further divided into sub-layers having the corresponding shear velocity computed by Eqs. (1) and (2). The result is the damped-elastic acceleration response spectrum, $\mathrm{SA}$, and it stems from the fixed depth within the shallow layers (mean foundation plane). Successively, the normalized acceleration response spectra, NSA, is obtained in relation to the response spectrum which refers to the outcropping bedrock. Discrete $\mathrm{NSA}_{T}$ values are sampled/selected in a 
spectral window where the amplification is significantly high for all the 1-D models representing the zones.

\subsubsection{Data-driven modelling}

The sampled/selected NSA values constitute the training and validation data set used in the multivariate regression analysis. The data set consists of 82 spectral series of six cover zones and two non-rigid bedrock zones, in which eight $\mathrm{NSA}_{T}$ values were selected, for a total of 648 training theoretical parameters. This data set refers to the application case of the hybrid model outlined below.

Eureqa Formulize (Schmidt and Lipson, 2009, 2013), which creates evolutionary equations using genetic programming, was used to develop the prediction model. This model is sustained by a sensitivity analysis in order to define the principal component regression (PCR). The principal components are: (i) the simulated average shear-wave velocities of the shallow layers, $\bar{V} s \mathrm{UP}$, (ii) the simulated elastic fundamental period $T_{0}$ and (iii) the identified periods, $T$. The first two are the endogenous variables directly related to the performance of the regression modelling, due to the fact that they are linked to the physical nature of the phenomena. In contrast, the spectral period $T$ is the exogenous variable introduced to identify the spectral position of the predicted $\mathrm{NSA}_{T}$ values.

Using the aforementioned variables, and by means of semi-automatic modelling, an effective and efficient regression model constituted by a bilinear-polynomial equation was developed. The equation of the prediction model in generic $x, y$ map points is

$\mathrm{NSA}_{T(x, y)}=a_{1} \bar{V} s_{(x, y)}^{\mathrm{UP}}+a_{2} T+\sum_{k=1}^{4} b_{k}\left(T_{0(x, y)}-T\right)^{k}$

where $a_{1}$ and $a_{2}$ are linear coefficients while $b_{k}$ are respectively the four coefficients of polynomial functions. For each 1-D layered model, the calibrated coefficients can be calculated by iterative methods, for example the least squares method, in order to minimize error. In reference to the physical nature of the spectral curves, the variables assumed in the polynomial of Eq. (9) promote a best-fitting performance. This variable is in relation to the fundamental period and it favours a flexible fitting of spectral shapes in large or small peak cases. However, in order to ensure a greater performance in the calibration phase, the theoretical spectral values must be selected in the window where the spectral amplification is substantial.

\subsection{Second-stage procedure in GCM}

The second stage of the GCM allows the $\operatorname{NSA}_{T(x, y)}$ spatial distribution to solve the regression equation (Eq. 9), having defined the best calibration coefficients. The fundamental period $T_{0(x, y)}$ is calculated in the first step (Eq. 8).
The spatial distribution of the simplified models from a regression analysis is characterized by an intrinsic jump effect along the border between two zones due to the different performance of the respective prediction models.

This effect is solved by means of an under-sampling via a dense regular mesh. Therefore, a subsequent redistribution of the $\operatorname{NSA}_{T(x, y)}$ values is obtained using a selected spatial interpolation technique.

\section{Application and results}

The hybrid model was applied in the built-up area of the San Giorgio del Sannio village in the Campania region of southern Italy. The area has a plain-hill morphology with a surface of $4.8 \mathrm{~km}^{2}$, a population density of 1500 people per square kilometres, and it is classified as being at high-level seismic hazard by the official Italian seismic hazard map (NTC, 2008). In addition, the location is close to active tectonic structures which have produced powerful earthquakes in the last 2 thousand years (Galadini and Galli, 2000).

\subsection{Lithological and geophysical features}

Pre-existing geological studies (Martelli et al., 2009) and field investigations highlight that the bedrock consists of Pliocene marine deposits, while the cover layers are Quaternary terrains deposited in a fluvio-lacustrine environment and more recent pyroclastic deposits. Together with the above qualitative data, depth investigations permitted the identification of lithological units that also took into account the rigidity of material. A total of 177 boreholes, with a depth from 10 to $40 \mathrm{~m}, 15$ multichannel analyses of surface waves (MASW), four down holes, and two $H / V$ spectral ratios from ambient noise records permitted an investigation of the cover layers and thus an identification of the following related litho-dynamic units (Fig. 4):

i. layer 1 - PIR, air-fall and/or flow pyroclastic deposits. The particle-size distribution characterizes them as being mono-granular sands. Thin layers of pumices of gravel size are frequently present;

ii. layer 2 - FLR, recent fluvio-lacustrine deposits consisting of loose sands;

iii. layer 3 - FLA, ancient fluvio-lacustrine deposits consisting of coarse grained and thinner package.

The bedrock is faulted. The dislocation placed it in contact with two deposits that have approximately the same age:

iv. layer 4a - SBC, thick, stratified granular deposits, mainly sandy conglomerates;

v. layer 4b-GRL, stiff blue clay/silt.

Units (iv) and (v) show characteristics of a non-rigid bedrock. 
a

Holocene -Pleistocene faults

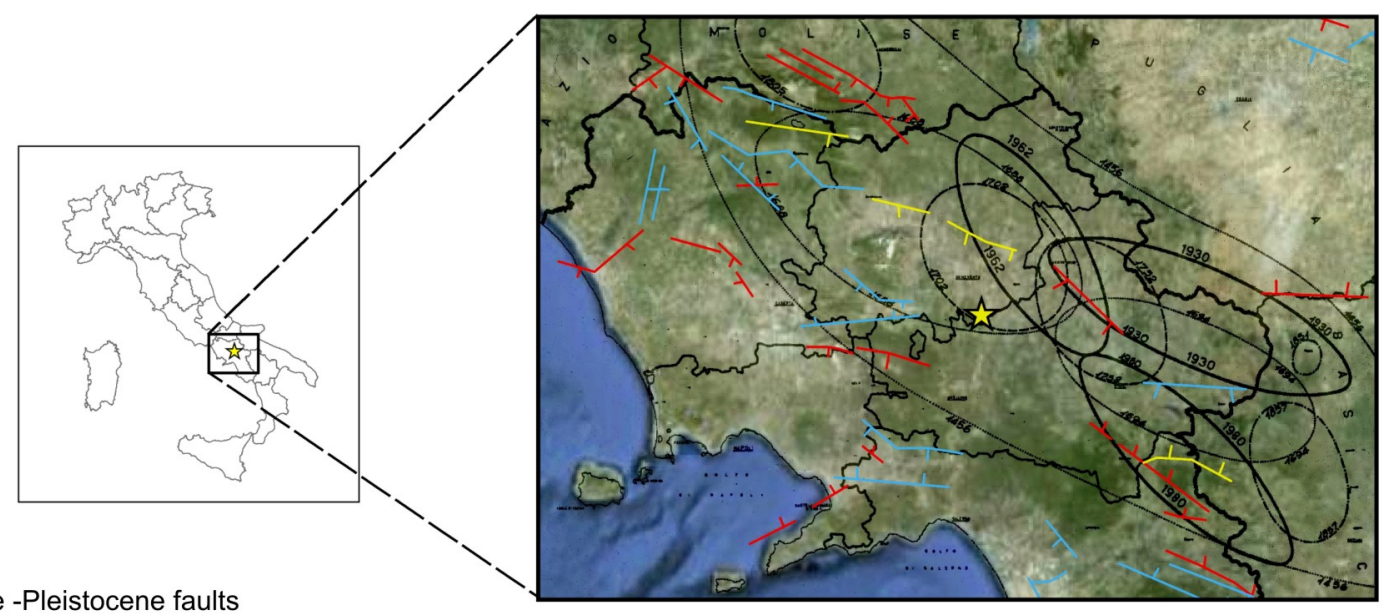

$\perp \perp$ active fault

presumed active fault

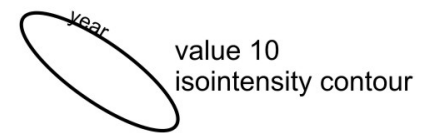

b
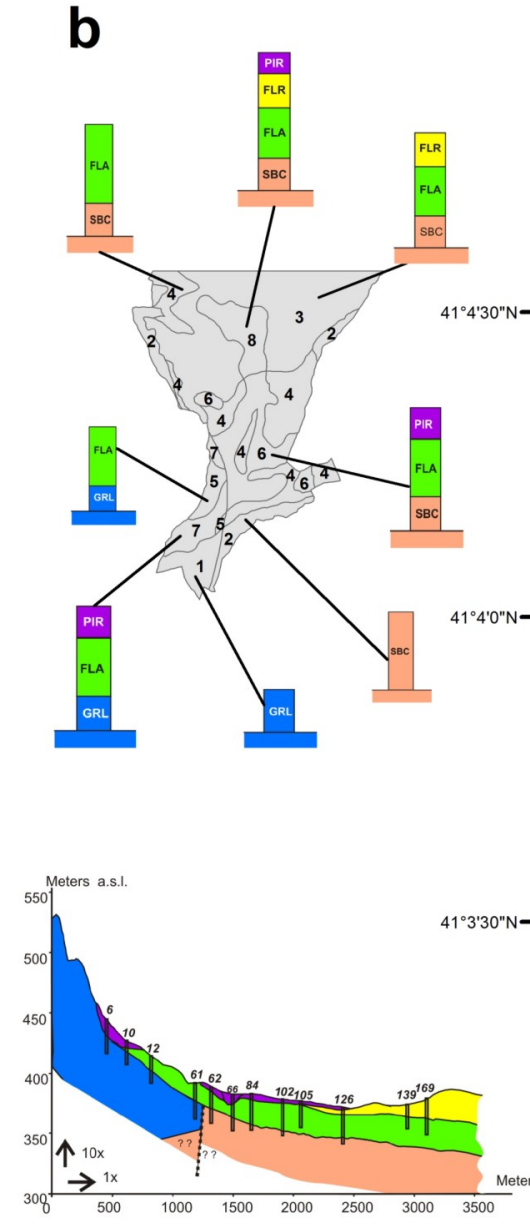

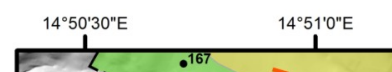

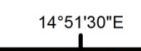

$1^{\circ 4^{\circ} 52^{\circ} 0^{\circ} \mathrm{E}}$
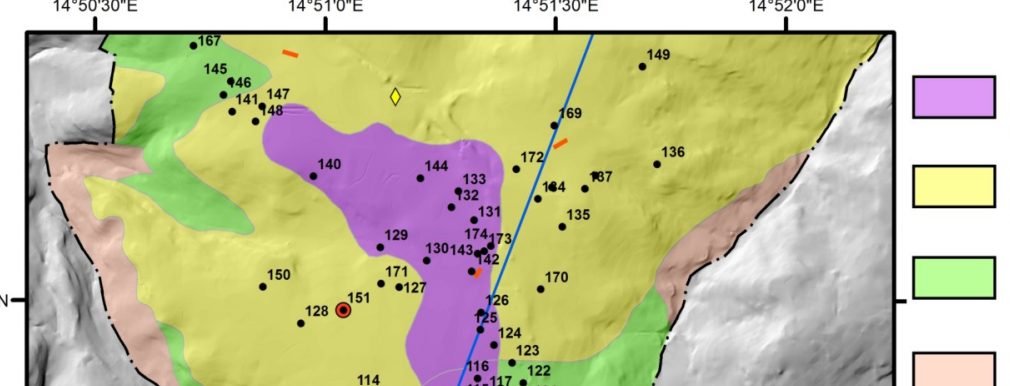

PIR, air-fall and/or flow pyroclastic deposits

Holocene

FLR, recent fluviolacustrine deposits Upper Pleistocene

FLA, ancient fluviolacustrine deposits
Middle-Lower Pleistocen

SBC, sandy

SBC, sandy
conglomeratic deposits Middle-Lower Pliocene

(1)

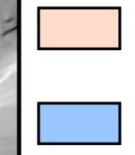

GRL, stiff blue clay/silt Lower Pliocene

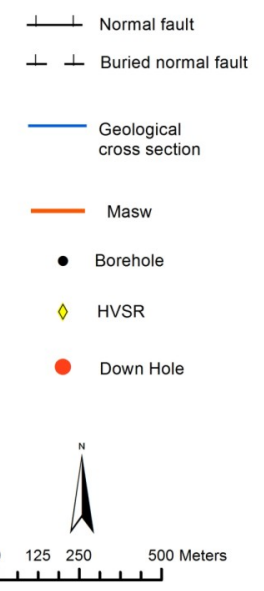

Figure 4. Seismology and geo-lithological setting of the study area: (a) historic earthquakes and tectonic genetic structures; (b) litho-dynamic units and survey distribution map, cross section and zones deriving from 1-D layer combination. 

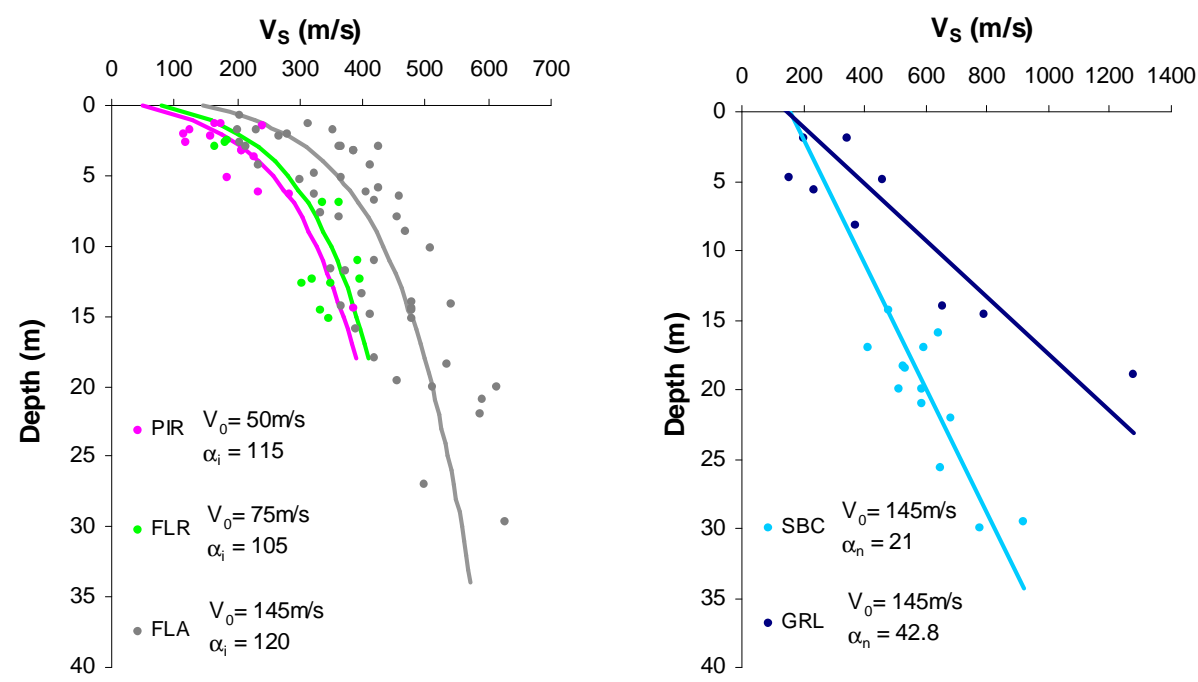

Figure 5. $V_{\mathrm{S}}$ depth-dependent curves of the litho-dynamic units: covered layers (left panel) and non-rigid bedrock (right panel).

\subsection{Model application and calibration}

The identified layered sequences determine the eight zones. Zone 1 and 2 are two bedrock layers, while the combinations of the cover layers define six zones from 3 to 8 , where the latter shows the litho-dynamic complete sequence (Fig. 4).

Based on the litho-dynamic units detected, the distribution of the thickness of the layers was determined by means of a "topo-to-raster" interpolation technique (Hutchinson, 1996) using the data points that defined the stratigraphic-log and geophysical surveys.

With regard to the cover layers, the depth distribution of the shear-wave velocities (Fig. 5) show low values for pyroclastic soils and recent fluvio-lacustrine deposits. In contrast, larger values are displayed in ancient fluvio-lacustrine deposits. A large amount of surveys exist for ancient fluviolacustrine deposits, due to the fact that these deposits are widely present in the whole area.

The depth distributions of shear-wave velocities within the bedrock layers have shown their non-rigid nature at shallow depths. Thickened granular stratified deposits, SBC, have shown a greater increase of depth-dependent shear-wave velocities than stiff blue clay/silt, GRL. Shear-wave velocity values at the bedrock are frequently detected in the undercover condition. However, in the linear regression analysis, an intercept value is imposed equal to the ancient fluviolacustrine deposits as foreseen by the model (Sect. 2.3).

Once completed, the structural and parametric matrix gives the possibility to define the average shear-wave velocities and thickness of the layers in accordance with the elastic fundamental period mapped in the GCM (Fig. 6).

The thickness distribution of the layers permits defining the limit values of the possible layered profiles characterizing the eight detected zones. On the basis of these values, the simulated-layered $V_{\mathrm{S}}$ profiles were generated using the
Monte Carlo technique (Fig. 7). In this way, the number of profiles is assumed taking into account the number and extension of the layers constituting the zone; 10-15 profiles were generated on these zones in which the cover layers were present. Subsequently, an additional half-division function of depth was performed for the simulated profile including the cover layer (zones from 3 to 8), while a multi-division was performed for the profiles simulating the outcropping bedrock (zones 1 and 2) (Fig. 7).

Using the simulated $V_{\mathrm{S}}$ profile, the numerical analysis of the seismic response was performed by means of the NERA code (Non-linear Earthquake site Response Analysis; Bardet and Tobita, 2001). The code makes it possible to resolve the seismic motion equation in the time domain taking into consideration the vertical propagation of the shear waves in a layered medium having a non-linear hysteretic stress-strain behaviour. The constitutive IM model implemented in NERA was proposed by Iwan (1967) and Mroóz (1967). This model foresees that the shear-stress-strain hysteretic loop follows the Masing model. The damping curve ratios are derived from normalized rigid module curves $G / G_{0}$ that cannot be introduced into the independent modality in contrast to the linear equivalent models. Experimental damping curves are usually used for a comparison with theoretical curves.

The input motion used in the response analysis was defined in accordance with regional seismic hazard studies as reported in technical regulations for constructions (NTC, 2008). The input motion is spectrum-compatible with the elastic horizontal spectral response acceleration corresponding to $10 \%$ exceedance probability over a 50 -year time interval; this spectrum refers to the life preservation state in normally crowded buildings. Disaggregation analysis, performed by Rexel 3.5 beta computer software (Iervolino et al., 2009), shows that the major hazard spectral contribution refers to earthquakes with a local magnitude between 6.5 


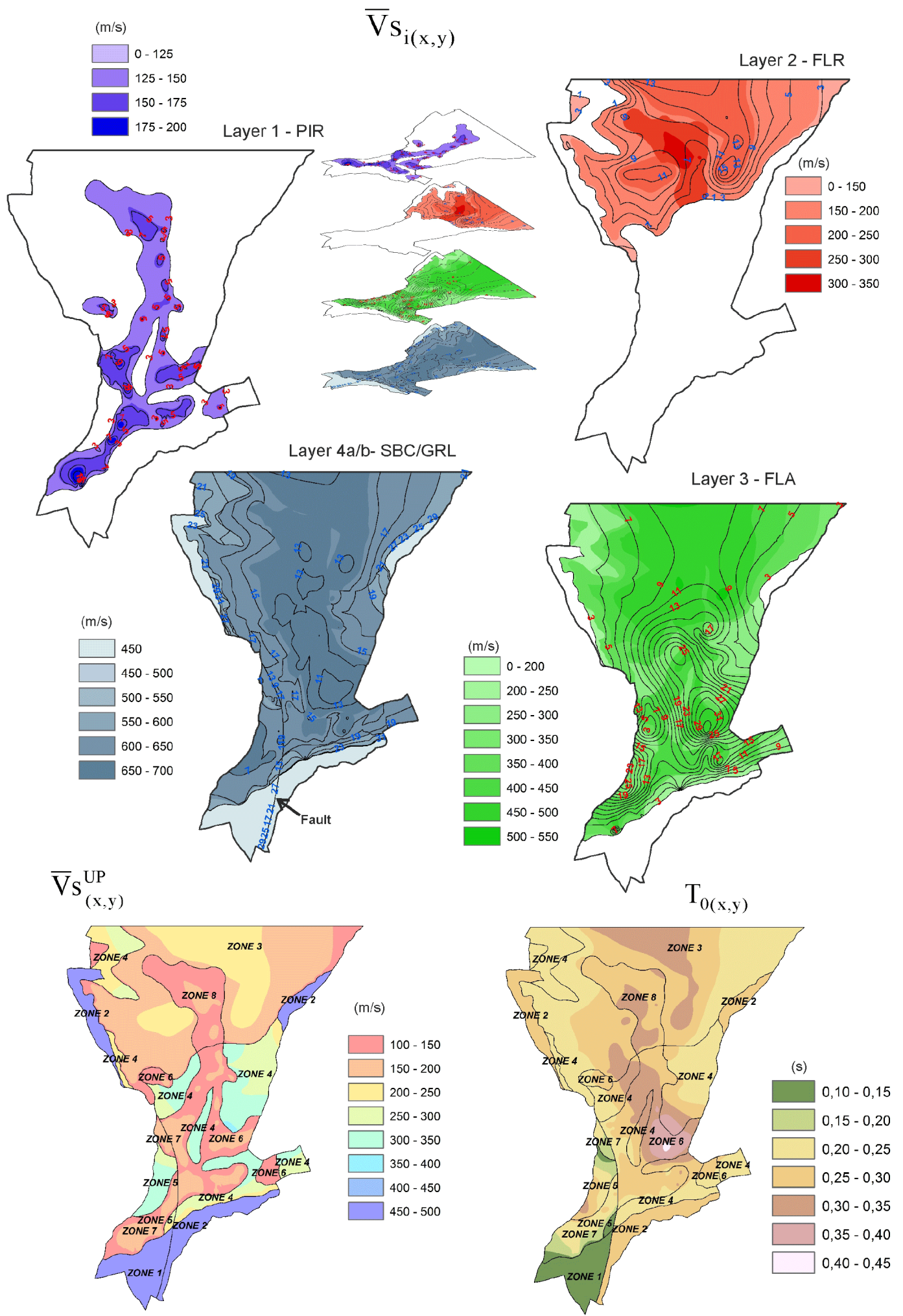

Figure 6. Maps resulting from the GCM; the average $V_{\mathrm{S}}$-layering maps report also the respective iso-thickness contours. 

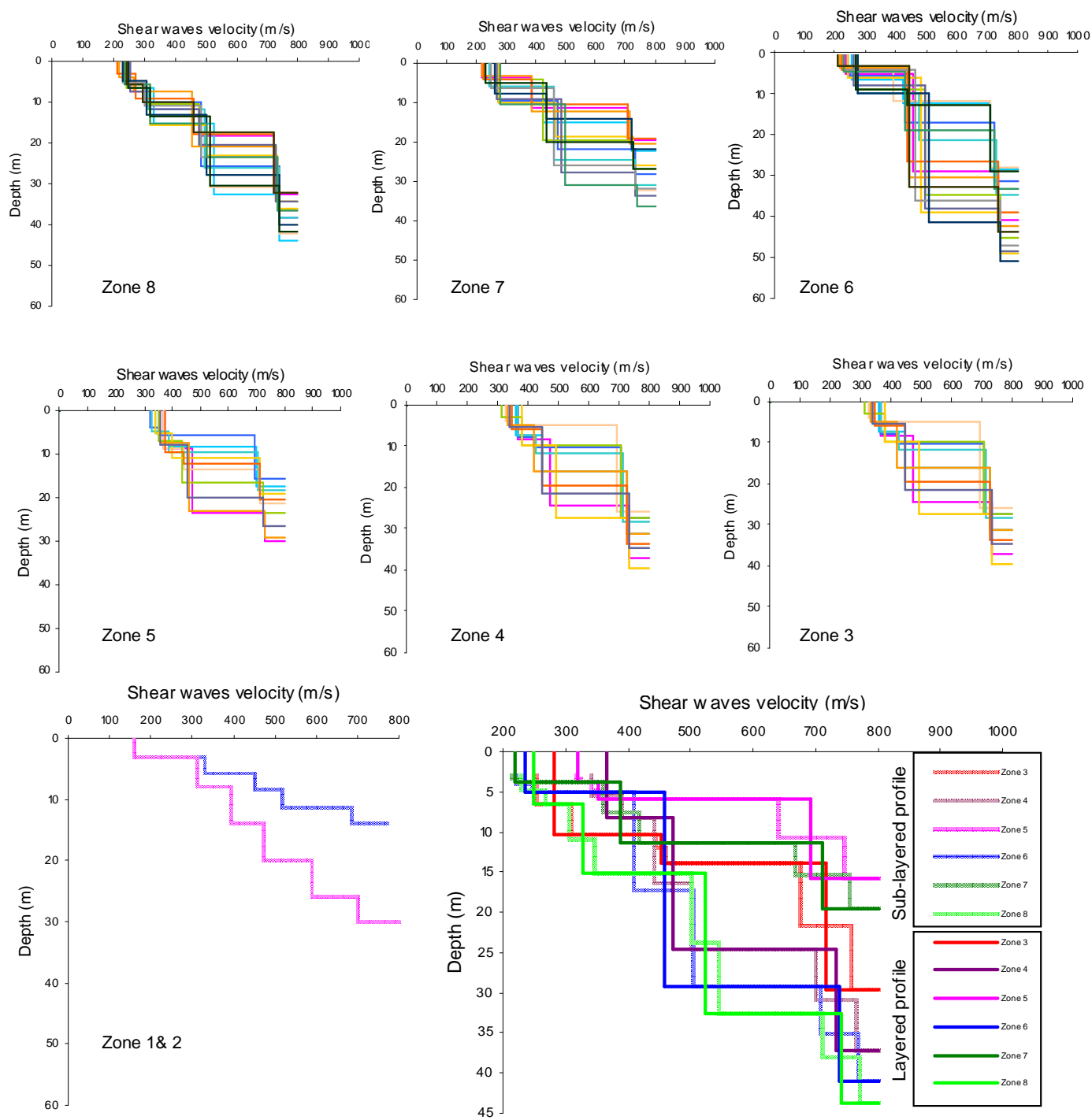

Figure 7. Simulated layered $V_{\mathrm{S}}$ profiles, generated using the Monte Carlo technique. An example of some sub-layer divisions used in the NERA analysis.

and 7.0 and a distance between 15 and $20 \mathrm{~km}$. Taking into account the aforementioned studies, the seismic input was obtained from the north-south component of the real-time history of the Irpinia earthquake (year 1980 with $M_{\mathrm{w}}=6.9$ ) recorded by the Bagnoli Irpino strong-motion station, located $20 \mathrm{~km}$ from the study area, with a epicentral distance of $30 \mathrm{~km}$ at the earthquake time.

Normalized shear modulus reduction and damping ratio curves were obtained from the literature regarding this subject (Guadagno et al., 1992 ; Zhang et al., 2005), taking into account lithology, grain size distribution and $V_{\mathrm{S}}$ or Standard Penetration Test (SPT) (Fig. 8).

The output acceleration response spectrum is defined at $5 \%$ of damping and it refers to a depth of $3 \mathrm{~m}$ from the ground surface. Eight $\mathrm{NSA}_{T}$ values were extracted from a sampling of $0.10 \mathrm{~s}$ within the period window $0.00 \mathrm{~s}$ Peak
Ground Acceleration (PGA) to $0.70 \mathrm{~s}$; in this range, most of the amplifications were shown for all the layered models (zones).

Therefore, $648 \mathrm{NSA}_{T}$ values were obtained for 82 series simulating the eight layered models; these values constitute an equal ratio of training and validation data set used in the multiple calibration coefficient analysis (Table 1) of the prediction model defined by Eq. (9). Therefore, the best performance of the model (Table 2) in regression analysis was detected in relation to minimum mean squared error.

The second step of the GCM determined the average shear-wave velocity raster of the shallow layers (Fig. 6), using the raster (Eq. 10). Subsequently, the $\mathrm{NSA}_{T(x, y)}$ rasters were obtained from Eq. (9) using the calibrated coefficient. Finally, the spatial smoothing of $\mathrm{NSA}_{T(x, y)}$ was performed by an under-sampling with a $50 \mathrm{~m}$ regular mesh (Fig. 9). 
Table 1. Best calibration coefficients of the metamodel.

\begin{tabular}{llllllll}
\hline $\begin{array}{l}\text { Predictor } \\
\text { coefficients }\end{array}$ & Zone 1 \& 2 & Zone 3 & Zone 4 & Zone 5 & Zone 6 & Zone 7 & Zone 8 \\
\hline$a_{1}$ & $2.22 \times 10^{-3}$ & $8.17 \times 10^{-3}$ & $4.56 \times 10^{-3}$ & $5.36 \times 10^{-3}$ & $7.71 \times 10^{-3}$ & $8.29 \times 10^{-3}$ & $8.74 \times 10^{-3}$ \\
$a_{2}$ & 1.761 & 1.135 & 0.209 & -0.520 & 1.509 & 1.266 & 1.769 \\
$b_{1}$ & 1.341 & 1.737 & 1.809 & 0.079 & 1.593 & 1.588 & 2.648 \\
$b_{2}$ & -3.981 & -10.39 & -1.652 & -4.28 & -7.507 & -5.115 & -6.953 \\
$b_{3}$ & 6.587 & -1.757 & -10.11 & -7.086 & 1.098 & -3.040 & -0.177 \\
$b_{4}$ & 29.08 & 39.732 & 0.795 & 1.756 & 30.663 & 9.78 & 30.154 \\
\hline
\end{tabular}

Table 2. Best performance parameters in regression coefficient analysis.

\begin{tabular}{lcccccccc}
\hline Best performance & Zone 1 \& 2 & Zone 3 & Zone 4 & Zone 5 & Zone 6 & Zone 7 & Zone 8 & Mean \\
\hline Correlation coefficient, $R$ & 0.871 & 0.832 & 0.853 & 0.853 & 0.863 & 0.922 & 0.925 & - \\
Maximum error & 0.204 & 0.444 & 0.497 & 0.314 & 0.332 & 0.303 & 0.367 & 0.352 \\
Mean squared error & 0.005 & 0.036 & 0.016 & 0.011 & 0.018 & 0.011 & 0.012 & 0.016 \\
Mean absolute error & 0.053 & 0.157 & 0.097 & 0.082 & 0.102 & 0.084 & 0.082 & 0.094 \\
\hline
\end{tabular}
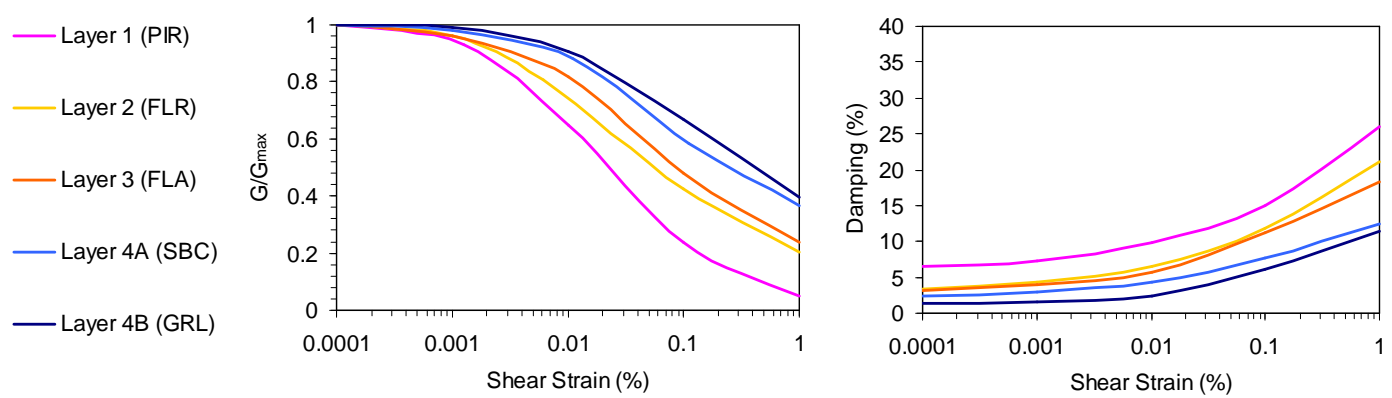

Figure 8. Strain-dependent curves of shear normalized modulus, $G / G_{0}$, and damping curves, $D / D_{0}$ extracted from: Guadagno et al. (1998) for PIR; Zhang et al. (2005) for FLR, FLA SBC and GRL.

\section{Validation and discussion}

The hybrid model is characterized by a sequence of physicalmathematical processes to produce simplified maps regarding spectral acceleration response values at different identified discrete periods. The simplification involves many components of the model, each of them influencing different degrees of the estimation/prediction performance of the very same model. These simplifications include:

i. the coherent identification in terms of $V_{\mathrm{S}}$-depth values distribution of the litho-dynamic units; in fact, in the identification of litho-dynamic units, that reflects the number of layers and consequently the zones, the modeller should associate an appropriate distribution of $V_{\mathrm{s}}-$ $z$ values; in some cases, this condition shows how the geophysical and geotechnical proprieties of soils can be decisive in the building of a GCM model in contrast to the exclusive recognition of lithologic typology;

ii. the efficiency of a prediction model (metamodel) for any given 1-D layered model zone: this aspect is connected to fitting errors which are ordinary in datadriven models;

iii. the uncertainties and approximations due to the 1-D numerical modelling when it is used contemporally with a complex-layering or topographic setting;

iv. in a lesser degree, the techniques used in the spatial distribution of layer thicknesses.

The efficiency performance of the hybrid model is validated on four down-hole locations where the stratigraphic-logs and the velocity profiles are experimentally known (Fig. 10). In this regard, we highlight that in the proposed computational model the data of down holes, as well as any data coming from direct or indirect geophysical tests, are used in the building and characterization of the model in the same way. Specifically, one or more seismic layers can be associated with one litho-dynamic unit, therefore $V_{\mathrm{s}}-h$ values are part of a cloud of values coming from different locations and in great part from different geophysical tests such as site-geotechnical correlation tests. In addition the 1-D $V_{\mathrm{s}}-h$ 

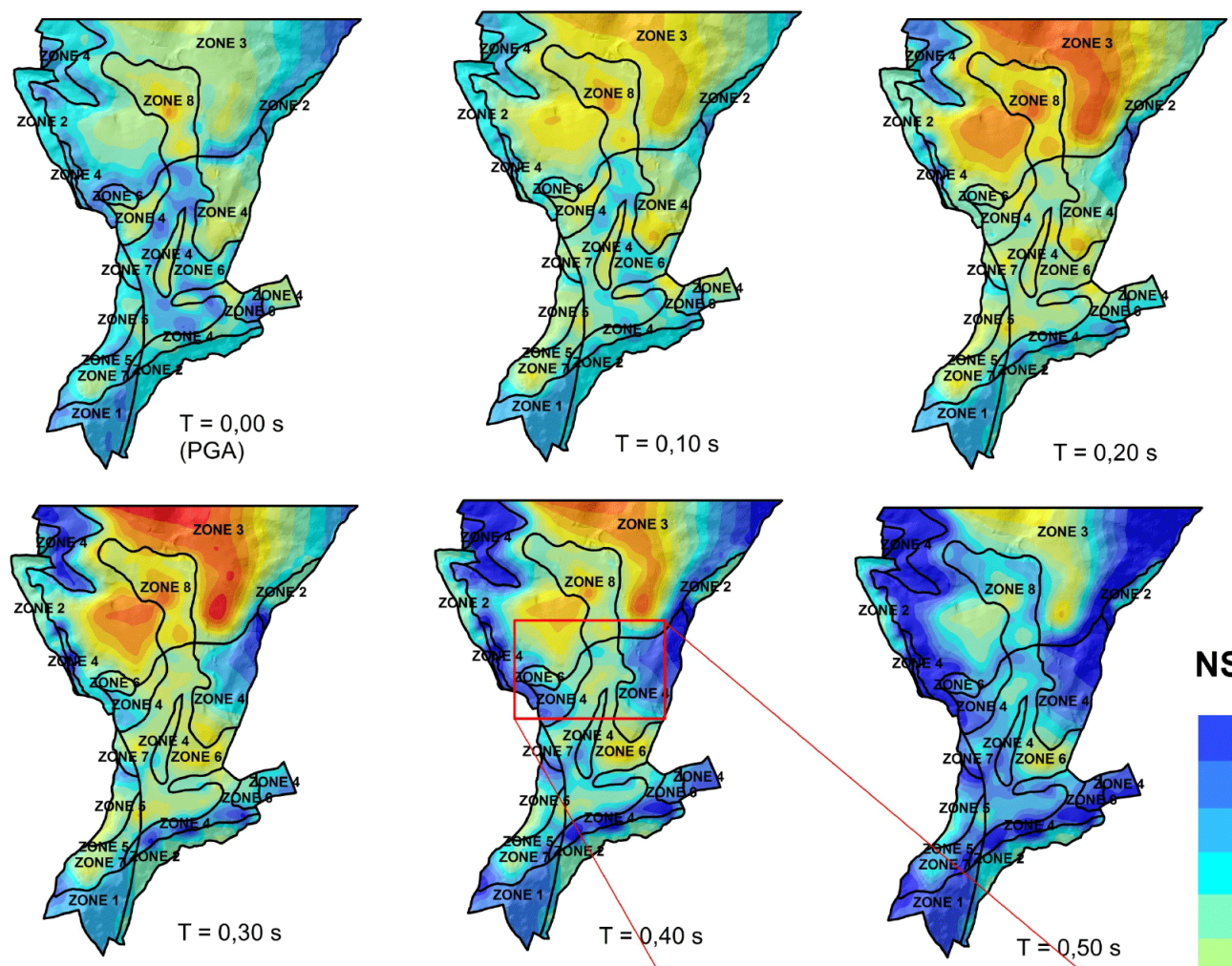

$\operatorname{NSA}_{\mathrm{T}(\mathrm{x}, \mathrm{y})}$
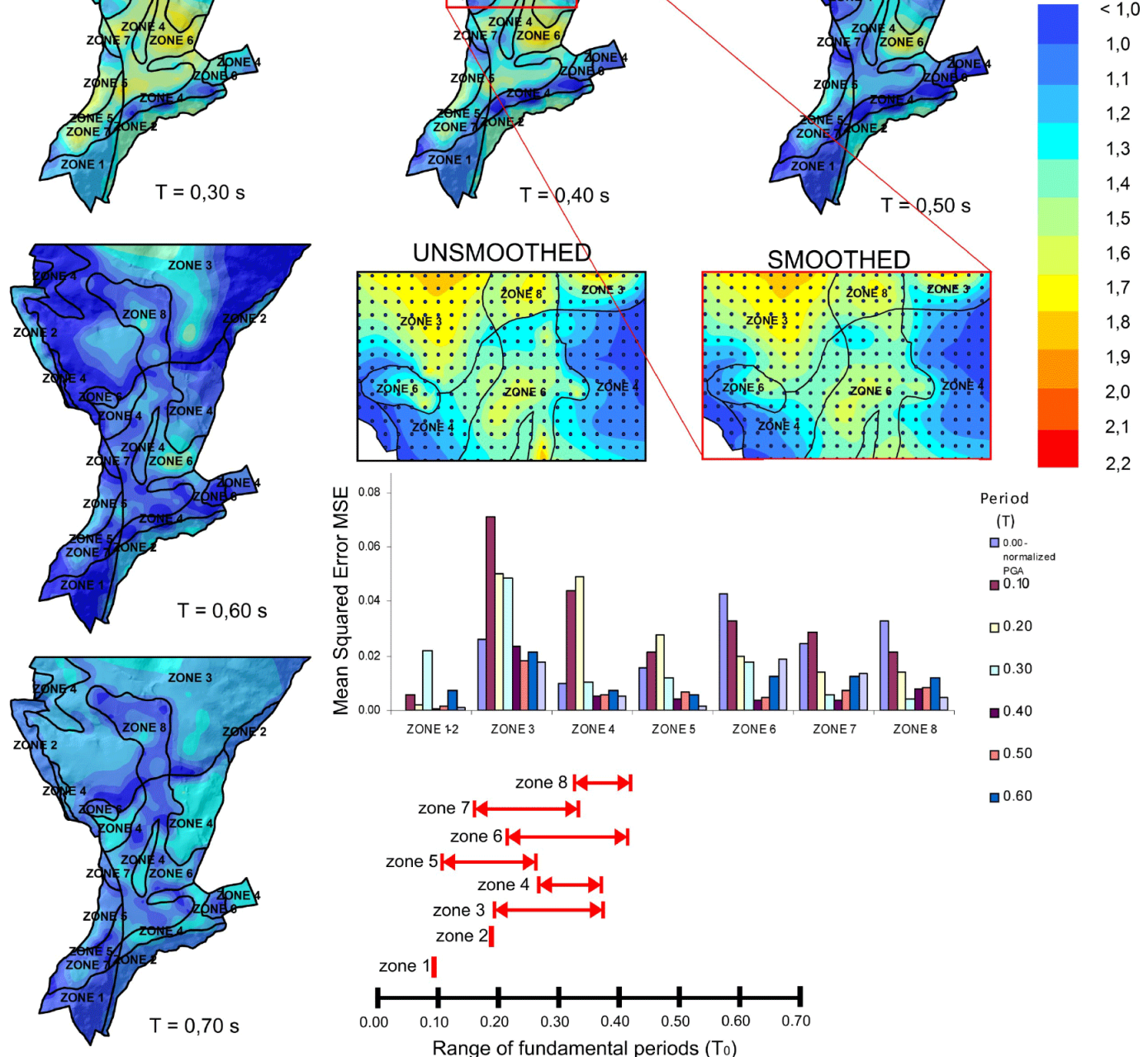

Figure 9. Maps of normalized acceleration response spectra, $\mathrm{NSA}_{T}$, with $5 \%$ damping; an example of spatial smoothing using an under sampled regular mash of $50 \mathrm{~m}$. In addition, the fitting errors in period-disaggregated analysis in terms of mean squared error are shown. 

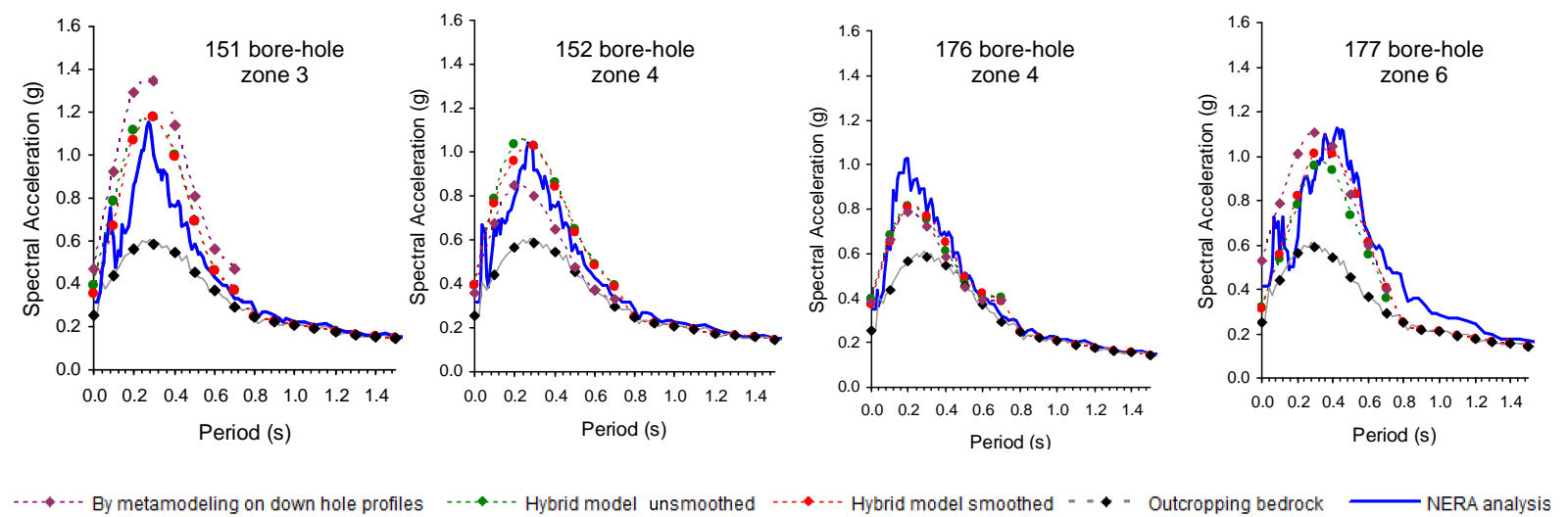

Figure 10. Back-validation analysis performed in comparison to four experimental $V_{\mathrm{S}}$ profiles.

models of zones used in the training of a hybrid model are obtained using the randomly driven Monte Carlo distribution technique; therefore, these training models can be more or less close to the seismic layer profiles detected by the specific site survey. Therefore, in terms of validation, down-hole data considered in input do not directly ensure a good fit between the model and down-hole input data responses.

In order to perform the aforementioned comparison test, the depth extension of some $V_{\mathrm{S}}$ profiles to the rigid bedrock was performed in relation to the spatial distribution of the rigid bedrock depth resulting from the GCM model. Thus, by comparing the spectral acceleration numerical response with the hybrid model $\mathrm{NSA}_{T(x, y)}$ values, a good validation feedback in the spectral amplification window (0.00-0.70 s) is highlighted. An almost similar approximation is shown with and without the spatial smoothing output. In addition, the validation test shows that the regression functions obtained by the metamodelling process can be directly used for the local definition of seismic response values in the same spectral periods chosen in the hybrid model. However, the $V_{\mathrm{S}}$ experimental profiles necessitate simplification in accordance with the 1-D layered model defined for the hybrid model processing. The identification of the average shear-wave velocity of the shallow layer, $\bar{V} s_{(x, y)}^{\mathrm{UP}}$, must be carried out with accuracy. This layer must be defined taking into consideration the lithology, both as a homogeneous material and as heterogeneous material sequence, in the same way as the corresponding litho-dynamic unit was identified in the hybrid model (Fig. 10).

The prediction model defined and tested on the eight layered-model series highlights a good degree of accuracy and precision, showing correlation coefficients, $R$, ranging between 0.83 and 0.92 . This short range, in addition to the low complexity of the regression function (Eq. 9) confers to the model the requirements of predictive accuracy and robustness. The efficacy of the predictors, $\bar{V} s_{(x, y)}^{\mathrm{UP}}$ and $T_{0}$, is supported by the fact that they are used in the definition of curves and abacuses regarding the estimation procedure of site amplification factors (Pergalani and Compagnoni, 2008).

Calculation of fitting errors of disaggregated spectral analysis (graphic in Fig. 9) shows that the fitting performance of the model is variable with the period and it seems that the error in several cases is greater nearer to PGA values and less near the fundamental periods. Such analysis should be carried out and reported in the $\mathrm{NSA}_{T(x, y)}$ maps, aimed at providing accuracy in estimation in relation to expected groundbuilding structure resonance.

In the study area the distribution of $\mathrm{NSA}_{T(x, y)}$ shows that for periods between 0.2 and $0.4 \mathrm{~s}$ the spectral amplification is the greatest reaching values near to 2.0 in the north sector where more recent fluvio-lacustrine deposits and a great thickness of covered-layer sequence are present. In addition, this spectral range is near to the fundamental vibration frequency of the majority of existing buildings.

\section{Conclusions}

This paper introduces a hybrid model with the purpose of mapping simplified local seismic response in areas characterized by stratified sequences featured by low geometrical complexity. This method is based on a GIS model, named GIS Cubic Model, and metamodelling processes.

The GCM is a layered model constructed for spatial calculation and distribution of 1-D models which are characterized by litho-dynamic units sequences. A litho-dynamic unit is a detected and defined lithological unit that is characterized by a shear-wave depth-dependent curve and consequently by non-linear stress-strain behaviour. The specific combination of the litho-dynamic sequences constitutes the "zone".

The metamodelling process carries out a regression analysis on data of local seismic responses from layered profiles that simulate the possible $V_{\mathrm{S}}$ profiles in a generically defined zone. In this work, we propose simulated profiles obtained using the Monte Carlo technique. 
The prediction model results from a metamodelling process, a bilinear polynomial mathematical shape in which the exogenous predictors are the shear-wave velocity of the shallow layer, $\bar{V} s_{(x, y)}^{\mathrm{UP}}$, and the fundamental period, $T_{0}$; the period $T$ constitutes the endogenous predictor detecting the spectral coordinates of the normalized spectral acceleration, $\mathrm{NSA}_{T(x, y)}$, within the spectral window where the amplification is shown.

The application and the development of the method was carried out in the urban area of the San Giorgio del Sannio village in Southern Italy. In this area a great number of geognostic and geophysical surveys are present in addition to up-to-date geological maps. All this information permits the use of 1-D numerical modelling of the seismic site response.

In this context, the metamodelling processes created an output data set of eight $V_{\mathrm{S}}$-layered simulated profiles that were processed through the NERA code. For all the areas, the prediction model proved to be sufficiently robust and accurate.

Moreover, a back-efficacy test was performed in zones where experimental profiles of four down holes were present. Depending on the case, test results highlighted a high-togood fit between the values of the spectral response of the hybrid model and those calculated from the physically based numerical model.

The hybrid model proposed and described in this paper is mainly a spatial computational tool able to deliver data regarding stratigraphic seismic response on the basis of the trained model built using geological, geotechnical and geophysical data set. Therefore, the success of the model in the seismic characterization of areas is strictly dependent on the abundance and quality of the data input and, at the same time, on the ability in the modelling design and data interpretation of the geoscientist or technical operator.

In conclusion, considering the nature of the mapped quantitative information, the hybrid model aspires to perform a third level of reliability (ISSMGE-TC 4, 1999); therefore it is able to deliver quantitative information in urban planning regarding the safety measures of pre-existing building infrastructure and regulate the designing of new infrastructure.

Acknowledgements. This research was financed by PRIN 20102011 (project 2010E89BPY_001 to F. M. Guadagno), and RISK Project (Risk Management via an Innovative System Based on Knowledge - Community Action Programme in the Field of Civil Protection). Authors thanks the two anonymous reviewers for their constructive reviews undertaken with extraordinary detailed and accuracy. We are grateful to Lee-Ann Bradley (US Geological Survey) for her suggestions and useful revision.

Edited by: R. Lasaponara

Reviewed by: G. P. Ganapathy and another anonymous referee

\section{References}

Al Yuncha, Z. and Luzon, F.: On the horizontal-to-vertical spectral ratio in sedimentary basins, B. Seismol. Soc. Am., 90, 11011106, 2000.

Bardet, J. P. and Tobita, T.: NERA: A Computer Program for Nonlinear Earthquake site Response Analyses of Layered Soil Deposits, University of Southern California, USA, 2001.

Bianchi Fasani, G., Cavinato, G. P., Petitta, M., Scarascia Mugnozza, G., and Voltaggio, M.: The geological model of Celano town area for seismic microzonation activities, Soil Dynam. Earthquake Eng., 28, 978-985, 2008

Bonnefoy-Claudet, S., Baize, S., Bonilla, L. F., Berge-Thierry, C., Pasten, C., Campos, J., Volant, P., and Verugo, R.: Site effect evaluation in the basin of Santiago de Chile using ambient noise measurements, Geophys. J. Int., 176, 925-937, 2009.

Doebling, S. W., Hemez, F. M., Schultze, J. F., and Cundy, A. L.: A metamodel-based approach to model validation for nonlinear finite element simulations, 20th International Modal Analysis Conference Los Angeles CA, ETATS-UNIS (February 2002), 4753, Los Angeles, 671-678, 2002.

EduPro Civil Systems: ProShake: Ground response analysis program, EduPro Civil Systems, Inc., Redmond, Washington, 1999.

FEMA 356: Prestandard and Commentary for the Seismic Rehabilitation of Buildings, prepared by the Building Seismic Safety Council for the Federal Emergency Management Agency 2000, Washington, D.C., 2000.

Galadini, F. and Galli, P.: Active tectonics in the Central Apennines (Italy) - Input data for seismic hazard Assessment, Nat. Hazards, 22, 225-270, 2000.

Ganapathy, G. P.: First level seismic microzonation map of Chennai city - a GIS approach, Nat. Hazards Earth Syst. Sci., 11, 549559, doi:10.5194/nhess-11-549-2011, 2011.

Grasso, S. and Maugeri, M.: The Seismic Microzonation of the City of Catania (Italy) for the Etna Scenario Earthquake $(M=6.2)$ of 20 February 1818., Earthquake Spectra, 28, 573-594, 2012.

Grelle, G. and Guadagno, F. M.: Regression analysis for seismic slope instability based on Double Phase Viscoplastic sliding model of the rigid block, Landslides, 10, 583-597, 2013.

Grelle, G., Revellino, P., and Guadagno, F. M.: Methodology for seismic and post-seismic stability assessing of natural clay slope based on a visco-plastic behavioural model in simplified dynamic analysis, Soil Dynam. Earthquake Eng., 12, 1248-1260, 2011.

Guadagno, F. M., Nunziata, C., and Rapolla, A.: Dynamic parameters of volcaniclastic soils and rocks of Campi Flegrei (Italy), in: Volcanic Seismology, IAVCEI Proceedings in Volcanology, 3, Springer-Verlag, 3, 533-546, 1992.

Hashemi, M. and Alesheikh, A. A.: Development and implementation of a GIS-based tool for spatial modeling of seismic vulnerability of Tehran, Nat. Hazards Earth Syst. Sci., 12, 3659-3670, doi:10.5194/nhess-12-3659-2012, 2012.

Hassanzadeh, R., Nedović-Budić, Z., Alavi Razavi, A., Norouzzadeh, M., and Hodhodkian, H.: Interactive approach for GISbased earthquake scenario development and resource estimation (Karmania hazard model), Comput. Geosci., 51, 324-338, 2013.

Hutchinson, M. F.: A locally adaptive approach to the interpolation of digital elevation models. In Proceedings, Third International Conference/Workshop on Integrating GIS and Environmental Modeling, Santa Barbara, CA, National Center for Geographic Information and Analysis, 
http://www.ncgia.ucsb.edu/conf/SANTA_FE_CD-ROM/sf_ papers/hutchinson_michael_dem/local.html (last access: 9 July 2014), 1996.

Idriss, I. M. and Sun, J. I.: User's Manual for SHAKE91, Center for Geotechnical Modeling, Department of Civil Engineering, University of California, Davis, 1992.

Iervolino, I., Galasso, C., and Cosenza, E.: REXEL: computer aided record selection for code-based seismic structural analysis, Bull. Earthquake Eng., 8, 339-362, 2009.

ISSMGE-TC4: Manual for zonation on seismic geotechnical hazards, M.C.E.E.R. 1995, The Japanese Society of Soil Mechanics and Foundation Engineering Multidisciplinary Center for Earthquake Engineering Research, ISSMGE-TC4: Manual for zonation on seismic geotechnical, The Japanese Society, 1993, revised 1999, http://www.dica.unict.it/Personale/Docenti/assets/ TC4Manual.pdf (last access: 9 July 2014), 1999.

Iwan, W. D.: On a Class of Models for the Yielding Behavior of Continuous and Composite Systems, J. Appl. Mech., 34, 612617, 1967.

Jimenez, M. J., Garcia-Fernadez, M., Zonno, G., and Cella, F.: Mapping Sol Effects In Barcelona, Spain, Through An Integrated Gis Environment, Soil Dynam. Earthquake Eng., 19, 289-301, 2000.

Kienzle, A., Hannich, D., Wirth, W., Ehret, D., Rohn, J., Ciugudean, V., and Czurda, K.: A GIS-based study of earthquake hazard as a tool for the microzonation of Bucharest, Eng. Geol., 87, 13-32, 2006.

Kolat, Ç., Doyuran, V., Ayday, C., and Lütfi Süzen, M.: Preparation of a geotechnical microzonation model using Geographical Information Systems based on Multicriteria Decision Analysis, Eng. Geol., 87, 241-255, 2006.

Maresca, R., Castellano, M., De Matteis, R., Saccorotti, G., and Vaccariello, P.: Local site effects in the town of Benevento (Italy) from noise measurements, Pure Appl. Geophys., 160, 17451764, 2003.

Martelli, G., Chiocchini, U., Potetti, M., Di Stefano, A., Critelli, S., Le Pera, E., Barbieri, M., and Madonna, S.: Carta Geologica d'Italia alla scala 1:50.000, Foglio 432 - Servizio Geologico d'Italia, http://www.isprambiente.gov.it/Media/carg/432_ BENEVENTO/Foglio.html (last access: 9 July 2014), 2009.

Mróz, Z.: On the description of anisotropic workhardening, J. Mech. Phys. Solids, 15, 163-175, 1967.
Mukhopadhyay, S. and Bormann, P.: Low cost seismic microzonation using microtremor data: an example from Delhi, India, J. Asian Earth Sci., 24, 271-280, 2004.

NTC - Norme Tecniche per le Costruzioni: DM 14 gennaio 008, Gazzetta Ufficiale, n. 29 del 4 febbraio 2008, Supplemento Ordinario n. 30, www.cslp.it, Istituto Poligrafico e Zecca dello Stato, Roma, 2008.

Papadimitriou, A. G., Antoniou, A. A., Bouckovalas, G. D., and Marinos, P. G.: Methodology for automated GIS-aided seismic microzonation studies, Comput. Geotech., 35, 505-523, 2008.

Pergalani, F. and Compagnoni, M.: A procedure for the evaluation of seismic local effects in Lombardia (Italy) for urban planning, The 14th World Conference on Earthquake Engineering 12-17 October 2008, Beijing, China, 2008.

Robertson, P. K., Sasitharan, S., Cunning, J. C., and Sego, D. C.: Shear-wave velocity to evaluate in-situ state of Ottawa sand, J. Geotech. Eng. 121, 262-303, 1995.

Schmidt, M. and Lipson, H.: Distilling Free-Form Natural Laws from Experimental Data, Science, 324, 81-85, 2009.

Schmidt, M. and Lipson, H.: Eureqa (Version 0.98 beta) [Software], available from: http://www.eureqa.com/ (last access: 9 July 2014), 2013.

Scott, J. B., Rasmussen, T., Luke, B., Taylor, W. J., Wagoner, J. L., Smith, S. B., and Louie, J. N.: Shallow Shear Velocity and Seismic Microzonation of the Urban Las Vegas, Nevada, Basin, B. Seismol. Soc. Am., 96, 1068-1077, 2006.

Sen, G. and Akyol, E.: A genetic-algorithm approach for assessing the liquefaction potential of sandy soils, Nat. Hazards Earth Syst. Sci., 10, 685-698, doi:10.5194/nhess-10-685-2010, 2010.

Tuladhar, R., Yamazaki, F., Warnitchai, P., and Saita, J.: Seismic microzonation of the greater Bangkok area using microtremor observations, Earthquake Eng. Struct. Dynam. 33, 211-225, 2004.

Turk, T., Gümüşay, U., and Tatar, O.: Creating infrastructure for seismic microzonation by Geographical Information Systems (GIS): A case study in the North Anatolian Fault Zone (NAFZ), Comput. Geosci., 43, 167-176, 2012

van Rossum, G. and Drake, F. L.: Python Reference Manual, available at: http://www.python.org, Python Labs, Virginia, USA, 2001.

Zhang, J., Andrus, R. D., and Juang, C. H.: Normalized shear modulus and material damping ratio relationships, J. Geotech. Geoenviron. Eng.-ASCE, 131, 453-464, 2005. 